\title{
Detection of susceptibility loci on APOA5 and COLEC12 associated with metabolic syndrome using a genome-wide association study in a Taiwanese population
}

\author{
Eugene Lin ${ }^{1,2,3}$, Po-Hsiu Kuo ${ }^{4}$, Yu-Li Liü ${ }^{5}$ Albert C. Yang ${ }^{6,7,8}$ and Shih-Jen Tsai, \\ ${ }^{1}$ Graduate Institute of Biomedical Sciences, China Medical University, Taichung, Taiwan \\ ${ }^{2}$ Vita Genomics, Inc., Taipei, Taiwan \\ ${ }^{3}$ TickleFish Systems Corporation, Seattle, WA, USA \\ ${ }^{4}$ Department of Public Health, Institute of Epidemiology and Preventive Medicine, National Taiwan University, Taipei, Taiwan \\ ${ }^{5}$ Center for Neuropsychiatric Research, National Health Research Institutes, Miaoli County, Taiwan \\ ${ }^{6}$ Department of Psychiatry, Taipei Veterans General Hospital, Taipei, Taiwan \\ ${ }^{7}$ Division of Psychiatry, National Yang-Ming University, Taipei, Taiwan \\ 8 Division of Interdisciplinary Medicine and Biotechnology, Beth Israel Deaconess Medical Center/Harvard Medical School, \\ Boston, MA, USA \\ Correspondence to: Eugene Lin, email: eugene.lin@vitagenomics.com \\ Shih-Jen Tsai, email: tsaib10913@gmail.com
}

Keywords: gene-gene interactions, genome-wide association studies, metabolic syndrome, single nucleotide polymorphisms, Pathology Section

Received: July 14, $2017 \quad$ Accepted: September 04, $2017 \quad$ Published: September 16, 2017

Copyright: Lin et al. This is an open-access article distributed under the terms of the Creative Commons Attribution License 3.0 (CC BY 3.0), which permits unrestricted use, distribution, and reproduction in any medium, provided the original author and source are credited.

\section{ABSTRACT}

Background: Although the association of single nucleotide polymorphisms (SNPs) with metabolic syndrome (MetS) has been reported in various populations in several genome-wide association studies (GWAS), the data is not conclusive. In this GWAS study, we assessed whether SNPs are associated with MetS and its individual components independently and/or through complex interactions in a Taiwanese population.

Methods: A total of 10,300 Taiwanese subjects were assessed in this study. Metabolic traits such as waist circumference, triglyceride, high-density lipoprotein (HDL) cholesterol, systolic and diastolic blood pressure, and fasting glucose were measured.

Results: Our data showed an association of MetS at the genome-wide significance level $\left(P<8.6 \times 10^{-8}\right)$ with two SNPs, including the rs662799 SNP in the apolipoprotein A5 (APOA5) gene and the rs16944558 SNP in the collectin subfamily member 12 (COLEC12) gene. Moreover, we identified the effect of APOA5 rs662799 on triglyceride and HDL, the effect of rs1106475 in the actin filament associated protein 1 like 2 (AFAP1L2) gene on systolic blood pressure, and the effect of rs17667932 in the mediator complex subunit 30 (MED30) gene on fasting glucose. Additionally, we found that an interaction between the APOA5 rs662799 and COLEC12 rs16944558 SNPs influenced MetS, high triglyceride, and low HDL.

Conclusions: Our study indicates that the APOA5 and COLEC12 genes may contribute to the risk of MetS and its individual components independently as well as through gene-gene interactions. 


\section{INTRODUCTION}

The metabolic syndrome (MetS), a chronic disease of metabolic dysregulation and a consequence of complicated interplay between genetic and environmental causes, is characterized by having large waist circumference plus two or more of the following physiologic abnormalities: raised triglyceride levels, low high-density lipoprotein (HDL) cholesterol levels, raised blood pressure, and raised glucose levels [1]. The manifestations of MetS encompass atherosclerosis, Alzheimer's disease, cancer, cognitive disorders, coronary artery disease (CAD), hypertension, insulin resistance, lipid metabolism, obesity, and type 2 diabetes $[2,3]$. Because of its escalating prevalence rate and an increased risk of chronic diseases such as CAD, MetS has become a leading public health concern in Taiwan and around the world as a result of excess energy intake and inactive lifestyles [2, 4]. In general, it has been estimated that at least one-quarter of the adult population has MetS worldwide [2]. We can certainly improve our long-term health by diagnosis MetS early with treatment [5]. Several lines of evidence support that MetS appears to be highly heritable [6]. In addition to making use of traditional candidate gene approaches, more and more genetic loci for MetS have been identified by leveraging hypothesis-free genome-wide association studies (GWAS) $[6,7]$. It has long been recognized that genetic variants conferring susceptibility to MetS may diversify across ethnicities $[6,7]$.

Several GWAS have been conducted to identify susceptible genetic loci affecting MetS as an entity (Supplementary Table S1) [8-13]. A previous GWAS study by Kraja $e t a l$. indicated that there was a significant association of MetS with the apolipoprotein A5 (APOA5), BUD13 homolog (BUD13), cholesteryl ester transfer protein $(C E T P)$, lipoprotein lipase $(L P L)$, and ZPR1 zinc finger $(Z P R 1)$ genes on data from 7 cohorts in Caucasian populations [8]. The following GWAS study by Kristiansson et al. reported that the ZPR1 rs964184 SNP may contribute to the susceptibility for MetS in Finnish cohorts [9]. Moreover, another GWAS study by Jeong et al. implicated that two SNPs including rs11216126 and rs 180349 may be involved with MetS susceptibility in a Korean population [10]. By using a GWAS analysis, Tekola-Ayele et al. also demonstrated that the rs 73989312 SNP near the carbonic anhydrase $10(C A 10)$ gene and the rs77244975 SNP in the catenin alpha 3 (CTNNA3) gene may be a determinant of MetS in an African population [11]. Finally, a recent GWAS study by Zhu et al. showed that the APOA5 rs651821 SNP and the rs671 SNP in the aldehyde dehydrogenase 2 family $(A L D H 2)$ gene are likely to influence MetS in Chinese subjects [12]. On the contrary, Zabaneh and Balding performed a GWAS study in a male Indian Asian population and detected no association of MetS with SNPs [13].

Based on a Taiwanese population, previous candidate-gene association studies showed a nominal association of MetS with several SNPs in the APOA5, $B U D 13, C E T P$, lipase A lysosomal acid type (LIPA), and five circadian clock genes including aryl hydrocarbon receptor nuclear translocator like (ARNTL), glycogen synthase kinase 3 beta $(G S K 3 B)$, period circadian clock 3 (PER3), RAR related orphan receptor A (RORA), RAR related orphan receptor $\mathrm{B}(R O R B)$; but none of these SNPs persisted significantly after performing Bonferroni correction $[14,15]$. To our knowledge, no GWAS studies have been evaluated in a Taiwanese population. Given that the known genetic variations explain only a fraction of the heritability for MetS $[9,12]$, we hypothesized that potential genetic biomarkers of MetS susceptibility remain to be discovered. Furthermore, the interplay between genes in affecting MetS traits have not been fully evaluated in previous GWAS of other populations. In light of the aforementioned considerations, we thus searched for MetS susceptibility loci by performing a GWAS study with MetS per se as well as with its individual components in Taiwanese individuals. We also determined whether significant gene-gene interactions exist between some key genes in influencing MetS and individual components.

\section{RESULTS}

Table 1 describes the demographic and clinical characteristics of the study population, including 1,811 MetS subjects and 8,489 non-MetS subjects. The MetS prevalence in our cohort was $17.6 \%$. As shown in Table 1, there was a significant difference in waist circumference, triglyceride, HDL, blood pressure, and fasting glucose between the MetS and non-MetS subjects (all $P<0.0001$, respectively).

As shown in Table 2, we identified two key SNPs, including APOA5 rs662799 and the rs16944558 SNP in the collectin subfamily member 12 (COLEC12) gene, associated with MetS per se at the genome-wide significance level $\left(P<8.6 \times 10^{-8}\right)$. As demonstrated in Table 2 for the APOA5 rs662799 SNP, there was an indication of an increased MetS risk among the MetS and non-MetS subjects after adjustment of covariates such as age and sex for the dominant model (odds ratio $(\mathrm{OR})=$ $1.40 ; 95 \%$ confidence interval $(\mathrm{CI})=1.27-1.56 ; P=1.2$ $\left.\mathrm{x} 10^{-10}\right)$. Similarly, there was an indication of an increased risk of MetS among the subjects after adjustment of covariates for the dominant model in the COLEC12 rs16944558 SNP $(\mathrm{OR}=1.40 ; 95 \% \mathrm{CI}=1.25-1.57 ; P=1.3$ $\left.\mathrm{x} 10^{-8}\right)$. The Manhattan and quantile-quantile (Q-Q) plots of GWAS for SNPs with MetS in terms of the dominant model is shown in Figures 1 and 2, respectively.

Next, we examined the SNPs with MetS traits as quantitative measures, including waist circumference, triglyceride, HDL, systolic blood pressure, diastolic blood pressure, and fasting glucose. As shown in Table 3 and Supplementary Table S2, there was evidence of an 
association between $A P O A 5$ rs662799 and triglyceride (additive model: $P=6.8 \times 10^{-84}$; dominant model: $P=7.2$ x $10^{-52}$; recessive model: $P=1.3 \times 10^{-67}$ ) at the genomewide significance level. Moreover, APOA5 rs662799 was associated with HDL (additive model: $P=2.8 \times 10^{-26}$; dominant model: $P=1.8 \times 10^{-30}$; recessive model: $P=5.7$ $\left.\mathrm{x} 10^{-18}\right)$ at the genome-wide significance level. Additionally, there was a significant difference in systolic blood pressure for the rs1106475 SNP in the actin filament associated protein 1 like 2 (AFAP1L2) gene (additive model: $P=$ $\left.7.68 \times 10^{-8}\right)$ as well as in fasting glucose for the rs17667932 SNP in the mediator complex subunit 30 (MED30) gene (additive model: $P=2.27 \times 10^{-14}$; recessive model: $P=2.28$ $\mathrm{x} 10^{-14}$ ) among the subjects after adjustment of covariates at the genome-wide significance level (Table 3). Moreover, there was evidence of an association between rs 17075725 in the glutamate metabotropic receptor 1 (GRM1) gene and waist circumference as well as between rs4893980 in the phosphodiesterase 11A (PDE11A) gene and diastolic blood pressure; however, this association did not reach genome-wide significance (Table 3). The Manhattan and Q-Q plots of GWAS for SNPs with MetS traits (including waist circumference, triglyceride, HDL, systolic blood pressure, diastolic blood pressure, and fasting glucose) in terms of the additive model are shown in Supplementary
Figures 1 - 12, respectively.

In addition, the generalized multifactor dimensionality reduction (GMDR) analysis was used to assess the impacts of combinations between two key SNPs (namely APOA5 rs662799 and COLEC12 rs16944558) in MetS and its individual components (as dichotomous measures) including age and sex as covariates. Table 4 summarizes the results obtained from GMDR analysis for two-way gene-gene interaction models in influencing MetS and its individual components with covariate adjustment. As shown in Table 4, there was a significant two-way model involving APOA5 rs662799 and COLEC12 rs16944558 $(P<0.001)$. The effects of these two-way models remained significant after Bonferroni correction $(P<0.05 / 6=0.008)$, indicating a potential gene-gene interaction between APOA5 and COLEC12 in influencing MetS. Moreover, there were two-way gene-gene interaction models in influencing individual components such as high triglyceride $(P<0.001)$ and low HDL $(P<0.001)$.

We further utilized multivariable logistic regression analysis with adjustment for age and sex to assess the two-way APOA5 rs662799 and COLEC12 rs16944558 interaction models selected by the GMDR method. As shown in Supplementary Table S3, the significant

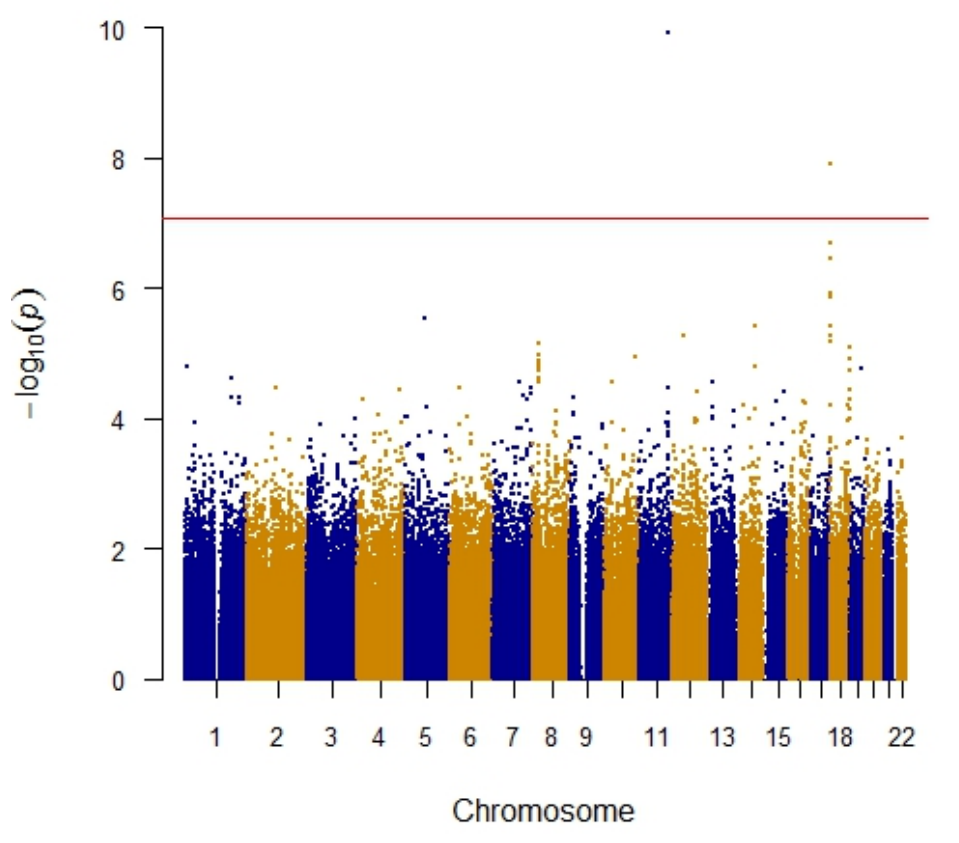

Figure 1: The Manhattan plot of genome-wide association of single nucleotide polymorphisms (SNPs) with the metabolic syndrome. The Manhattan plot was constructed using the $P$ values of SNPs, which was generated via logistic regression after adjustment for covariates including age and sex. The individual SNP is represented by a point, with higher points (higher negative $\log _{10} P$ values) indicating more significant association. The red horizontal line is the genome-wide significance level $\left(P=8.6 \times 10^{-8}\right)$, and points above the red horizontal line indicate SNPs with a P value of less than $8.6 \times 10^{-8}$. Y-axis: $-\log _{10}(P$ value $)$ of each SNP; X-axis: chromosomes labelled with blue and orange colors. 
Table 1: Demographic and clinical characteristics of study subjects.

\begin{tabular}{|c|c|c|c|}
\hline Characteristic & Without MetS & With MetS & $P$ value \\
\hline No. of subjects $(n)$ & 8,489 & 1,811 & \\
\hline Age (years) & $48.8 \pm 11.3$ & $53.1 \pm 10.5$ & $<0.0001$ \\
\hline Sex $($ male $\%)$ & $47.6 \%$ & $52.2 \%$ & 0.0004 \\
\hline Waist circumference $(\mathrm{cm})$ & $82.0 \pm 9.0$ & $94.1 \pm 8.3$ & $<0.0001$ \\
\hline Triglyceride $(\mathrm{mg} / \mathrm{dl})$ & $101.8 \pm 68.8$ & $196.5 \pm 132.0$ & $<0.0001$ \\
\hline $\operatorname{HDL}(\mathrm{mg} / \mathrm{dl})$ & $55.2 \pm 12.8$ & $43.3 \pm 9.3$ & $<0.0001$ \\
\hline Systolic blood pressure (mmHg) & $114.8 \pm 16.5$ & $129.4 \pm 17.2$ & $<0.0001$ \\
\hline Diastolic blood pressure (mmHg) & $71.4 \pm 10.5$ & $79.4 \pm 11.2$ & $<0.0001$ \\
\hline Fasting glucose $(\mathrm{mg} / \mathrm{dl})$ & $93.6 \pm 16.4$ & $110.7 \pm 34.1$ & $<0.0001$ \\
\hline
\end{tabular}

$\mathrm{HDL}=$ high-density lipoprotein cholesterol, MetS = metabolic syndrome.

Data are presented as mean \pm standard deviation.

Table 2: Odds ratio analysis with odds ratios after adjustment for covariates between the MetS and two SNPs (including $A P O A 5$ rs662799 and $C O L E C 12$ rs16944558) with genome-wide significance.

\begin{tabular}{|c|c|c|c|c|c|c|c|c|c|c|c|c|c|}
\hline \multirow{2}{*}{ Gene } & \multirow{2}{*}{ SNP } & \multirow{2}{*}{ Chr } & \multirow{2}{*}{ A1 } & \multirow{2}{*}{ A2 } & \multicolumn{3}{|c|}{ Additive model } & \multicolumn{3}{|c|}{ Dominant model } & \multicolumn{3}{|c|}{ Recessive model } \\
\hline & & & & & OR & $95 \% \mathrm{CI}$ & $P$ & OR & $95 \% \mathrm{CI}$ & $P$ & OR & $95 \% \mathrm{CI}$ & $P$ \\
\hline APOA5 & rs662799 & 11 & G & A & 1.25 & $1.14-1.37$ & $3.7 \times 10^{-6}$ & 1.40 & $1.27-1.56$ & $1.2 \times 10^{-10}$ & 1.35 & $1.13-1.62$ & 0.0012 \\
\hline COLEC12 & rs16944558 & 18 & $\mathrm{~T}$ & $\mathrm{C}$ & 1.20 & $1.12-1.30$ & $1.2 \times 10^{-6}$ & 1.40 & $1.25-1.57$ & $1.3 \times 10^{-8}$ & 1.18 & $1.04-1.34$ & 0.0101 \\
\hline
\end{tabular}

$\mathrm{A} 1=$ minor allele, $\mathrm{A} 2=$ major allele, $\mathrm{Chr}=$ chromosome, $\mathrm{CI}=$ confidence interval, $\mathrm{MetS}=$ metabolic syndrome, $\mathrm{OR}=\mathrm{odds}$ ratio.

Analysis was obtained after adjustment for covariates including age and sex. $P$ values of $<8.6 \times 10^{-8}$ (genome-wide significance) are shown in bold.

interactions were confirmed by logistic regression models (MetS: $P=2.3 \times 10^{-7}$; high triglyceride: $P=2.0 \times 10^{-16}$; low HDL: $\left.P=2.3 \times 10^{-16}\right)$.

Finally, statistical power analysis revealed that the present study had a $99.9 \%$ power to detect associations of APOA 5 rs662799 and COLEC12 rs16944558 with MetS among the MetS and non-MetS subjects.

\section{DISCUSSION}

Our GWAS analysis is the first study to date to track down whether the main effects of SNPs are significantly associated with the risk of MetS and its individual components independently and/or through gene-gene

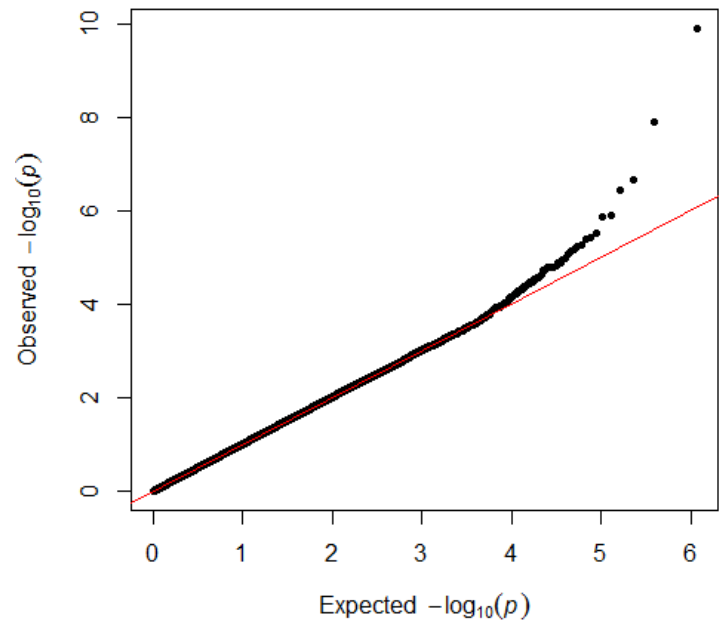

Figure 2: The QQ-plot of metabolic syndrome results. The plots show observed and expected distributions of $P$-values from the genome-wide association study of the metabolic syndrome. 
Table 3: Linear regression models of associations between individual components of the MetS and top SNPs (that is, one SNP per gene with the smallest $P$ value).

\begin{tabular}{|c|c|c|c|c|c|c|c|c|c|c|c|c|c|}
\hline \multirow{2}{*}{ Gene } & \multirow{2}{*}{ SNP } & \multirow{2}{*}{ Chr } & \multirow{2}{*}{ A1 } & \multirow{2}{*}{ A2 } & \multicolumn{3}{|c|}{ Additive model } & \multicolumn{3}{|c|}{ Dominant model } & \multicolumn{3}{|c|}{ Recessive model } \\
\hline & & & & & BETA & SE & $P$ & BETA & SE & $P$ & BETA & SE & $P$ \\
\hline \multicolumn{14}{|c|}{ (a) Waist circumference } \\
\hline GRMI & rs 17075725 & 6 & A & G & 2.469 & 0.5125 & $1.48 \times 10^{-6}$ & 0.1784 & 0.2417 & 0.4606 & 4.946 & 1.024 & $1.39 \times 10^{-6}$ \\
\hline \multicolumn{14}{|c|}{ (b) Triglyceride } \\
\hline$A P O A 5$ & rs662799 & 11 & G & A & 32.91 & 1.68 & $6.8 \times 10^{-84}$ & 26.54 & 1.74 & $7.2 \times 10^{-52}$ & 57.51 & 3.29 & $1.3 \times 10^{-67}$ \\
\hline \multicolumn{14}{|l|}{ (c) HDL } \\
\hline APOA5 & rs662799 & 11 & G & A & -2.47 & 0.23 & $2.8 \times 10^{-26}$ & -2.75 & 0.24 & $1.8 \times 10^{-30}$ & -3.92 & 0.45 & $5.7 \times 10^{-18}$ \\
\hline \multicolumn{14}{|c|}{ (d) Diastolic blood pressure } \\
\hline PDE11A & rs4893980 & 2 & $\mathrm{~T}$ & $\mathrm{C}$ & 1.228 & 0.2511 & $1.02 \times 10^{-6}$ & 0.2741 & 0.2095 & 0.1907 & 2.461 & 0.4967 & $7.34 \times 10^{-7}$ \\
\hline \multicolumn{14}{|c|}{ (e) Systolic blood pressure } \\
\hline AFAP1L2 & rs1106475 & 10 & $\mathrm{~T}$ & $\mathrm{C}$ & 1.693 & 0.3148 & $7.68 \times 10^{-8}$ & 0.7763 & 0.3058 & 0.01115 & 3.245 & 0.6153 & $1.37 \times 10^{-7}$ \\
\hline \multicolumn{14}{|c|}{ (f) Fasting glucose } \\
\hline MED30 & rs17667932 & 8 & $\mathrm{C}$ & $\mathrm{T}$ & 30.29 & 3.962 & $2.27 \times 10^{-14}$ & 1.044 & 0.9626 & 0.278 & 60.57 & 7.923 & $2.28 \times 10^{-14}$ \\
\hline
\end{tabular}

$\mathrm{BETA}=$ Beta coefficients, $\mathrm{Chr}=$ chromosome, $\mathrm{HDL}=$ high-density lipoprotein cholesterol, MetS = metabolic syndrome, $\mathrm{SE}$ $=$ standard error.

Analysis was obtained after adjustment for covariates including age and sex. $P$ values of $<8.6 \times 10^{-8}$ (genome-wide significance) are shown in bold.

interactions among Taiwanese individuals. In this study, we pinpointed that APOA5 rs662799 and COLEC12 rs16944558 were linked with MetS at the genome-wide significance level. Additionally, we identified APOA5 rs662799 as a genome-wide significant locus for the individual components of MetS such as triglyceride and HDL. Our data also indicated that there was a genomewide significant association of AFAP1L2 rs1106475 with systolic blood pressure as well as a genome-wide significant association of MED30 rs17667932 with fasting glucose. Finally, gene-gene interactions of $A P O A 5$ and $C O L E C 12$ may contribute to the risk of MetS, high triglyceride, and low HDL.

In the present study, we found that the APOA5 rs662799 SNP may play an important role in the modulation of MetS in a Taiwanese population by using a GWAS study. In addition, we observed that there was a genome-wide significant association of $A P O A 5$ rs662799 with triglyceride and HDL. The APOA5 gene is located on chromosome 11q23 and encodes an apolipoprotein protein that has been indicated in regulating the plasma triglyceride levels, a major risk factor for CAD [14]. Although the APOA5 rs662799 polymorphism has been widely implicated to affect the MetS risk, the relationship between the MetS and APOA5 rs662799 has been ambiguous [14]. Our results are in agreement with those of several other studies [14, 16-22]. The APOA5 rs662799 SNP has been reported to increase the risk of developing MetS in Caucasians [16], Japanese [17],
Taiwanese [14, 18], Hong Kong [19], Chinese [20], and Korean [21] populations. However, some studies in Arabic [23], Caucasian [24-26], and Hispanic [27] populations have shown contrasting findings in comparison to the current study. Several meta-analysis studies have also suggested that the APOA5 rs662799 SNP is associated with an elevated risk of acquiring MetS in Asians, but not in European populations [20, 22]. Moreover, $\mathrm{Xu}$ et al. performed a meta-analysis on data from 91 studies including 51,868 subjects in Asian, European, and other ethnic populations and detected a significant association of APOA5 rs662799 with triglyceride and HDL [20]. This association also remained significant after the subgroup analysis stratified by the ethnicity including both Asian and European populations [20]. It should be pointed out that the $\mathrm{G}$ allele frequency of APOA5 rs662799 differs noticeably between various ethnic populations, ranging from $27.58 \%$ in the present Taiwanese population, $7.14 \%$ in British subjects, 35.58\% in Japanese subjects, $12.3 \%$ in African American subjects, to $25.73 \%$ in Han Chinese subjects as shown in public data from the 1000 Genomes Project (Supplementary Table S4).

In the present study, we found a genome-wide significant association of MetS with the COLEC12 rs16944558 SNP in a Taiwanese population by using a GWAS study. The COLEC12 gene is located on chromosome $18 \mathrm{p} 11.32$ and encodes a scavenger receptor protein, which is implicated in several functions linked with host defense [28]. It has been shown that the 
Table 4: Two-way gene-gene interaction models by using the GMDR method with adjustment for age and sex.

\begin{tabular}{|l|l|c|c|}
\hline \multicolumn{1}{|c|}{ Phenotype } & \multicolumn{1}{|c|}{ Two-way interaction model } & Testing accuracy (\%) & $\boldsymbol{P}$ value \\
\hline MetS & APOA5 rs662799, COLEC12 rs16944558 & 53.98 & $<\mathbf{0 . 0 0 1}$ \\
\hline High waist circumference $^{\mathrm{a}}$ & APOA5 rs662799, COLEC12 rs16944558 & 50.34 & 0.335 \\
\hline High triglyceride $^{\mathrm{b}}$ & $A P O A 5$ rs662799, COLEC12 rs16944558 & 58.72 & $<\mathbf{0 . 0 0 1}$ \\
\hline Low HDL $^{\mathrm{c}}$ & APOA5 rs662799, COLEC12 rs16944558 & 55.30 & $<\mathbf{0 . 0 0 1}$ \\
\hline High blood pressure $^{\mathrm{d}}$ & APOA5 rs662799, COLEC12 rs16944558 & 49.71 & 0.652 \\
\hline High fasting glucose $^{\mathrm{e}}$ & APOA5 rs662799, COLEC12 rs16944558 & 50.15 & 0.461 \\
\hline
\end{tabular}

GMDR $=$ generalized multifactor dimensionality reduction, $\mathrm{HDL}=$ high-density lipoprotein cholesterol, $\mathrm{MetS}=$ metabolic syndrome.

$\mathrm{P}$ value was based on 1,000 permutations. Analysis was obtained after adjustment for covariates including age and sex.

$P$ values of $<0.008$ (Bonferroni correction: 0.05/6) are shown in bold.

${ }^{a}$ Waist circumference $\geq 90 \mathrm{~cm}$ in male subjects, waist circumference $\geq 80 \mathrm{~cm}$ in female subjects.

b Triglyceride $\geq 150 \mathrm{mg} / \mathrm{dl}$.

${ }^{c} \mathrm{HDL}<40 \mathrm{mg} / \mathrm{dl}$ in male subjects, HDL $<50 \mathrm{mg} / \mathrm{dl}$ in female subjects.

d Systolic blood pressure $\geq 130 \mathrm{mmHg}$ or diastolic blood pressure $\geq 85 \mathrm{mmHg}$.

${ }^{\mathrm{e}}$ Fasting glucose $\geq 100 \mathrm{mg} / \mathrm{dl}$.

COLEC12 gene plays a role in mediating the uptake of oxidized low density lipoprotein in vascular endothelial cells, indicating its association with lipid metabolism, one of the hallmarks of MetS [28, 29]. It has also been proposed that the COLEC12 gene is involved in the clearance of amyloid beta, suggesting its contribution to Alzheimer's disease [30]. Furthermore, MetS has been correlated with age-related mental disorders such as Alzheimer's disease in previous studies [31,32]. Thus, we speculate that COLEC12 may contribute to susceptibility to MetS because MetS is in turn associated with lipid metabolism and Alzheimer's disease. It should be noted that the T allele frequency of COLEC12 rs16944558 varies considerably between different ethnic populations, ranging from $44.16 \%$ in the present Taiwanese population, $9.34 \%$ in British subjects, $39.42 \%$ in Japanese subjects, $22.95 \%$ in African American subjects, to $44.66 \%$ in Han Chinese subjects (Supplementary Table S4).

In this study, another finding was a positive association of AFAP1L2 rs1106475 with systolic blood pressure at the genome-wide significance level. The AFAP1L2 gene, also known as XB130, is located on chromosome 10q25.3 and encodes an adaptor protein that can affect downstream proteins in signaling pathways even though the adaptor protein lacks enzyme catalytic activity $[33,34]$. Previous studies have shown that the AFAP1L2 gene is involved in gene regulation, cell growth, cell migration, cell survival, and cell invasion via the cAMP-cSrc-phosphoinositide 3-kinase/Akt pathway [33, 34]. The AFAP1L2 gene was also found to be associated with tumorigenesis in multiple studies [35,36]. It is of note that the AFAP1L2 gene has been proposed to interact with the telomeric repeat binding factor 1 (TERF1) gene, which mediates telomerase and telomere functions [37]. Moreover, it has previously been reported that telomere length was associated with systolic blood pressure and hypertension [38, 39]. Thus, we speculate that AFAP1L2 may contribute to susceptibility to systolic blood pressure because the gene-gene interaction between AFAPIL2 and TERF1 may in turn influence systolic blood pressure.

On another note, our analysis indicated that there was a genome-wide significant association of MED30 rs17667932 with fasting glucose. The MED30 gene is located on chromosome 8q24.11 and encodes one of the subunits of the Mediator complex, which is involved in various processes for transcription such as the organization of chromatin architecture [40]. Studies have shown that the Mediator complex is associated with various diseases such as glucose metabolism, lipid metabolism, cardiovascular disease (CVD), metabolic disorders, and neurological disorders [41, 42]. In an animal study, Krebs et al. reported that a mutation in the MED30 gene results in lethal cardiomyopathy in the mouse heart, indicating a potential role of MED30 in human CVD-related metabolic disorders [43].

By using the GMDR approach, we further inferred the epistatic effects between APOA5 and COLEC12 in influencing MetS and its individual components such as high triglyceride and low HDL. To our knowledge, no other study has been conducted to evaluate genegene interactions between these two genes. Besides the statistical significance, the potential biological mechanism under the interaction models was our concern. The functional relevance of the interactive effects of $A P O A 5$ and COLEC12 on MetS, high triglyceride, and low HDL remains to be elucidated. It was further speculated that the APOA5 and COLEC12 genes may be involved in the same pathways or pathology. It has been reported that overexpression of human $A P O A 5$ in mice is correlated with decreased plasma triglyceride levels in an animal study [44]. Likewise, it has been shown that APOA5 rs662799 is involved in the regulation of gene transcription due to its location in the promoter region and thereby considerably impact serum apolipoprotein A5 levels [17]. Moreover, both $A P O A 5$ and $C O L E C 12$ are known to play a key role in lipid metabolism [8, 28, 29]. 
This study has both strengths and limitations. The main weakness is that the results regarding $A P O A 5$ did not represent novel findings although they were confirmed by other independent populations. On the other hand, the other novel findings relevant to COLEC12, AFAP1L2, and $M E D 30$ were not verified by other independent populations. Thus, our observations require much more research to assess if the findings are replicated in diversified ethnic populations [45, 46]. In future work, prospective clinical trials with other ethnic populations are necessary to facilitate a thorough evaluation of the association and interactions of the investigated SNPs with MetS and its individual components [47-49]. By contrast, a major strength of our study is that we employed rigorously phenotyped MetS cases and healthy controls without MetS from the Taiwan Biobank to assess genegene interactions between the investigated genes.

\section{CONCLUSIONS}

In conclusion, we carried out a GWAS analysis of the association as well as gene-gene interactions with MetS and its individual components in Taiwanese subjects. Our findings demonstrate that the APOA5 and COLEC12 genes may affect the prevalence of MetS independently and through complex gene-gene interactions. Furthermore, the APOA5, AFAP1L2, and MED30 genes are a determinant of MetS component factors such as triglyceride, HDL, systolic blood pressure, and fasting glucose. Independent replication studies with larger sample sizes is essential to provide further insights into the role of these genes investigated in this study.

\section{MATERIALS AND METHODS}

\section{Study population}

This study included Taiwanese subjects from the Taiwan Biobank [14, 15, 32, 50-55]. This biobank collected specimens and associated data from the general Taiwanese population with no history of cancer through recruitment centers across Taiwan during 2013-2015 [14, $15,32,50-55]$. This biobank is mainly funded by the Taiwanese government and aims to provide researchers with opportunities for collaboration to facilitate public health-related research concerning local common chronic diseases [50]. The study cohort consisted of 10,300 participants. Individuals who could perform activities of daily living, were aged 30-70 years, and were selfreported as being of Taiwanese Han Chinese ancestry were included in this study [51]. Individuals with a history of cancer or nonresidents of Taiwan were excluded [51]. Ethical approval for the study was granted by the Institutional Review Board of the Taiwan Biobank before conducting the study. Each subject signed the approved informed consent form. All experiments were performed in accordance with relevant guidelines and regulations.

\section{Metabolic syndrome}

Measurements of metabolic traits (including as waist circumference, triglyceride, high-density lipoprotein cholesterol, systolic and diastolic blood pressure, and fasting glucose) were obtained when participants underwent general health examinations [14, 50, 51]. To assess MetS, we used the International Diabetes Federation definition, which requires that the participant represented by central obesity (defined as waist circumference $\geq 90 \mathrm{~cm}$ in male subjects and $\geq 80 \mathrm{~cm}$ in female subjects) plus the presence of two or more of the following four components: (1) triglycerides $\geq 150 \mathrm{mg} / \mathrm{dl}$; (2) HDL cholesterol $<40$ $\mathrm{mg} / \mathrm{dl}$ in male subjects and $<50 \mathrm{mg} / \mathrm{dl}$ in female subjects; (3) systolic blood pressure $\geq 130 \mathrm{mmHg}$ or diastolic blood pressure $\geq 85 \mathrm{mmHg}$; and (4) fasting plasma glucose $\geq$ $100 \mathrm{mg} / \mathrm{dl}$ [56]. Two measurements of blood pressure were taken in both arms at least 10-15 minutes apart in the sitting position. These measurements were averaged to obtain the final blood pressure used in this study.

\section{Genotyping}

DNA was isolated from blood samples using a QIAamp DNA blood kit following the manufacturer's instructions (Qiagen, Valencia, CA, USA). The quality of the isolated genomic DNA was evaluated using agarose gel electrophoresis, and the quantity was determined by spectrophotometry [57]. SNP genotyping was carried out using the custom Taiwan BioBank chips and run on the Axiom Genome-Wide Array Plate System (Affymetrix, Santa Clara, CA, USA). To efficiently obtain maximal genetic information from Taiwanese Han Chinese samples, the custom Taiwan BioBank chips were designed by using SNPs on the Axiom Genome-Wide CHB 1 Array (Affymetrix, Inc., Santa Clara, CA, USA) with minor allele frequencies (MAFs) $\geq 5 \%$, by using SNPs in exons with MAFs $>10 \%$ on the Human Exome BeadChip (Illumina, Inc., San Diego, CA, USA), and by using SNPs previously reported in ancestry information panels, cancer studies, and pharmacogenetic studies [51]. To appraise the performance of the custom Taiwan BioBank chip, 70 unrelated Taiwanese individuals were genotyped by using both the custom Taiwan BioBank chip and the Axiom Genome-Wide CHB 1 Array and a high average concordance rate of $99.55 \%$ was obtained for the SNPs in the 70 subjects [51].

In this study, quality criteria for SNP exclusion from further analyses were the following: due to failure to achieve Hardy-Weinberg equilibrium $\left(\mathrm{P}<1 \times 10^{-6}\right)$, due to a genotyping call rate $<90 \%$, or due to $\mathrm{MAF}<1 \%$. After 
the quality control procedure, a total of 583,469 SNPs were used as the basis for SNP function prediction.

\section{Statistical analysis}

Categorical data were evaluated using the chi-square test. We conducted the Student's t-test to compare the difference in the means from two continuous variables. To estimate the association of the investigated SNP with MetS, we conducted a logistic regression analysis to evaluate the ORs and their $95 \%$ CIs, adjusting for covariates including age and sex [58]. Furthermore, we estimated the association of the investigated SNP with individual components of MetS by using logistic regression analysis, adjusting for age and sex [59]. The genotype frequencies were assessed for Hardy-Weinberg equilibrium using a $\chi^{2}$ goodness-of-fit test with 1 degree of freedom (i.e. the number of genotypes minus the number of alleles). Multiple testing was adjusted by the Bonferroni correction. The criterion for significance was set at $\mathrm{P}<0.05$ for all tests. Data are presented as the mean \pm standard deviation.

To investigate gene-gene interactions, we employed the GMDR method [60]. We tested two-way interactions using 10-fold cross-validation. The GMDR software provides some output parameters, including the testing accuracy and empirical $P$ values, to assess each selected interaction. Moreover, we provided age and sex as covariates for gene-gene interaction models in our interaction analyses. Permutation testing obtains empirical $P$ values of prediction accuracy as a benchmark based on 1,000 shuffles. In order to correct for multiple testing, we applied a conservative Bonferroni correction factor for the number of tests employed in the GMDR analysis.

Based on the effect sizes in this study, the power to detect significant associations was evaluated by QUANTO software (http://biostats.usc.edu/Quanto.html). The Manhattan and Q-Q plots were drawn by using the $\mathrm{R}$ package 'qqman'.

\section{Author contributions}

Study conception and design: EL and SJT. Acquisition of data: PHK, YLL, and ACY. Analysis and interpretation of data: EL and SJT. Draft manuscript: EL. All authors read and approved the final manuscript.

\section{ACKNOWLEDGEMENTS AND GRANT SUPPORT}

The authors extend their sincere thanks to Vita Genomics, Inc. for funding this research. This work was supported by the Ministry of Economic Affairs in Taiwan (SBIR Grant S099000280249-154; EL), by Taipei Veterans General Hospital, Taiwan (Grants VGHUST103-G1-4-1,
V105C-008, and V105E17-002-MY2-1; SJT), by National Health Research Institutes, Taiwan (Grant NP-105-SP-04; YLL), and by the Ministry of Science and Technology, Taiwan (Grant MST 102-2314-B-002-117-MY3; PHK). In addition, we thank Alex Tsai for English editing.

\section{CONFLICTS OF INTEREST}

The authors declare no potential conflicts of interests.

\section{REFERENCES}

1. Tan CE, Ma S, Wai D, Chew SK, Tai ES. Can we apply the National Cholesterol Education Program Adult Treatment Panel definition of the metabolic syndrome to Asians? Diabetes Care. 2004; 27: 1182-6.

2. Kaur J. A comprehensive review on metabolic syndrome. Cardiol Res Pract. 2014; 2014: 943162. doi: 10.1155/2014/943162.

3. Prasad H, Ryan DA, Celzo MF, Stapleton D. Metabolic syndrome: definition and therapeutic implications. Postgrad Med. 2012; 124: 21-30. doi: 10.3810/pgm.2012.01.2514.

4. Mottillo S, Filion KB, Genest J, Joseph L, Pilote L, Poirier P, Rinfret S, Schiffrin EL, Eisenberg MJ. The metabolic syndrome and cardiovascular risk a systematic review and meta-analysis. J Am Coll Cardiol. 2010; 56: 1113-32. doi: 10.1016/j.jacc.2010.05.034.

5. Hoffman EL, VonWald T, Hansen K. The metabolic syndrome. S D Med. 2015; Spec No: 24-8.

6. Abou Ziki MD, Mani A. Metabolic syndrome: genetic insights into disease pathogenesis. Curr Opin Lipidol. 2016; 27: 162-71. doi: 10.1097/MOL.0000000000000276.

7. Povel CM, Boer JM, Reiling E, Feskens EJ. Genetic variants and the metabolic syndrome: a systematic review. Obes Rev. 2011; 12: 952-67. doi: 10.1111/j.1467789X.2011.00907.x.

8. Kraja AT, Vaidya D, Pankow JS, Goodarzi MO, Assimes TL, Kullo IJ, Sovio U, Mathias RA, Sun YV, Franceschini N, Absher D, Li G, Zhang Q, et al. A bivariate genomewide approach to metabolic syndrome: STAMPEED consortium. Diabetes. 2011; 60: 1329-39. doi: 10.2337/ db10-1011.

9. Kristiansson K, Perola M, Tikkanen E, Kettunen J, Surakka I, Havulinna AS, Stancakova A, Barnes C, Widen E, Kajantie E, Eriksson JG, Viikari J, Kahonen M, et al. Genome-wide screen for metabolic syndrome susceptibility Loci reveals strong lipid gene contribution but no evidence for common genetic basis for clustering of metabolic syndrome traits. Circ Cardiovasc Genet. 2012; 5: 242-9. doi: 10.1161/CIRCGENETICS.111.961482.

10. Jeong SW, Chung M, Park SJ, Cho SB, Hong KW, Genome-wide association study of metabolic syndrome in koreans. Genomics Inform. 2014; 12: 187-94. doi: 10.5808/ 
GI.2014.12.4.187.

11. Tekola-Ayele F, Doumatey AP, Shriner D, Bentley AR, Chen G, Zhou J, Fasanmade O, Johnson T, Oli J, Okafor G, Eghan BA Jr, Agyenim-Boateng K, Adebamowo C, et al. Genome-wide association study identifies African-ancestry specific variants for metabolic syndrome. Mol Genet Metab. 2015; 116: 305-13. doi: 10.1016/j.ymgme.2015.10.008.

12. Zhu Y, Zhang D, Zhou D, Li Z, Li Z, Fang L, Yang M, Shan Z, Li H, Chen J, Zhou X, Ye W, Yu S, et al. Susceptibility loci for metabolic syndrome and metabolic components identified in Han Chinese: a multi-stage genome-wide association study. J Cell Mol Med. 2017; 21: 1106-16. doi: 10.1111/jcmm.13042.

13. Zabaneh D, Balding DJ. A genome-wide association study of the metabolic syndrome in Indian Asian men. PLoS One. 2010; 5: e11961. doi: 10.1371/journal.pone.0011961.

14. Lin E, Kuo PH, Liu YL, Yang AC, Kao CF, Tsai SJ. Association and interaction of APOA5, BUD13, CETP, LIPA and health-related behavior with metabolic syndrome in a Taiwanese population. Sci Rep. 2016; 6: 36830. doi: 10.1038/srep36830.

15. Lin E, Kuo PH, Liu YL, Yang AC, Kao CF, Tsai SJ. Effects of circadian clock genes and health-related behavior on metabolic syndrome in a Taiwanese population: Evidence from association and interaction analysis. PLoS One. 2017; 12: e0173861. doi: 10.1371/journal.pone.0173861.

16. Maasz A, Kisfali P, Horvatovich K, Mohas M, Marko L, Csongei V, Farago B, Jaromi L, Magyari L, Safrany E, Sipeky C, Wittmann I, Melegh B. Apolipoprotein A5 T-1131C variant confers risk for metabolic syndrome. Pathol Oncol Res. 2007; 13: 243-7.

17. Yamada Y, Kato K, Hibino T, Yokoi K, Matsuo H, Segawa T, Watanabe S, Ichihara S, Yoshida H, Satoh K, Nozawa Y. Prediction of genetic risk for metabolic syndrome. Atherosclerosis. 2007; 191: 298-304. doi: 10.1016/j. atherosclerosis.2006.05.035.

18. Hsu LA, Ko YL, Chang CJ, Teng MS, Wu S, Hu CF. Apolipoprotein A5 gene $-1131 \mathrm{~T} / \mathrm{C}$ polymorphism is associated with the risk of metabolic syndrome in ethnic Chinese in Taiwan. Clin Chem Lab Med. 2008; 46: 1714-9. doi: 10.1515/CCLM.2008.352.

19. Ong KL, Jiang CQ, Liu B, Jin YL, Tso AW, Tam S, Wong KS, Tomlinson B, Cheung BM, Lin JM, Yue XJ, Lam KS, Lam TH, et al. Association of a genetic variant in the apolipoprotein A5 gene with the metabolic syndrome in Chinese. Clin Endocrinol (Oxf). 2011; 74: 206-13. doi: 10.1111/j.1365-2265.2010.03899.x.

20. Xu C, Bai R, Zhang D, Li Z, Zhu H, Lai M, Zhu Y. Effects of APOA5 -1131T $>$ C (rs662799) on fasting plasma lipids and risk of metabolic syndrome: evidence from a casecontrol study in China and a meta-analysis. PLoS One. 2013; 8: e56216. doi: 10.1371/journal.pone.0056216.

21. Kim YR, Hong SH. Association of Apolipoprotein A5 Gene Polymorphisms with Metabolic Syndrome in the Korean
Population. Genet Test Mol Biomarkers. 2016; 20: 130-6. doi: 10.1089/gtmb.2015.0250.

22. Liu CF, Yang QF, Chen XL, Liu CY. Apolipoprotein a5 gene polymorphism and risk for metabolic syndrome: a meta-analysis. Genet Test Mol Biomarkers. 2012; 16: 12415. doi: 10.1089/gtmb.2012.0183.

23. Komurcu-Bayrak E, Onat A, Poda M, Humphries SE, Palmen J, Guclu F, Can G, Erginel-Unaltuna N. Gendermodulated impact of apolipoprotein A5 gene (APOA5) $-1131 \mathrm{~T}>\mathrm{C}$ and c.56C $>\mathrm{G}$ polymorphisms on lipids, dyslipidemia and metabolic syndrome in Turkish adults. Clin Chem Lab Med. 2008; 46: 778-84. doi: 10.1515/ CCLM.2008.161.

24. Grallert H, Sedlmeier EM, Huth C, Kolz M, Heid IM, Meisinger C, Herder C, Strassburger K, Gehringer A, Haak M, Giani G, Kronenberg F, Wichmann HE, et al. APOA5 variants and metabolic syndrome in Caucasians. J Lipid Res. 2007; 48: 2614-21. doi: 10.1194/j1r.M700011-JLR200.

25. Niculescu LS, Vladica M, Sima AV. Association of APOA5 and APOC3 gene polymorphisms with plasma apolipoprotein A5 level in patients with metabolic syndrome. Biochem Biophys Res Commun. 2010; 391: 587-91. doi: 10.1016/j.bbrc.2009.11.103.

26. Fallah MS, Sedaghatikhayat B, Guity K, Akbari F, Azizi F, Daneshpour MS. The Relation between Metabolic Syndrome Risk Factors and Genetic Variations of Apolipoprotein V in Relation with Serum Triglyceride and HDL-C Level. Arch Iran Med. 2016; 19: 46-50.

27. Mattei J, Demissie S, Tucker KL, Ordovas JM. Apolipoprotein A5 polymorphisms interact with total dietary fat intake in association with markers of metabolic syndrome in Puerto Rican older adults. J Nutr. 2009; 139: 2301-8. doi: 10.3945/jn.109.109900.

28. Ohtani K, Suzuki Y, Eda S, Kawai T, Kase T, Keshi H, Sakai Y, Fukuoh A, Sakamoto T, Itabe H, Suzutani T, Ogasawara M, Yoshida I, et al. The membrane-type collectin CL-P1 is a scavenger receptor on vascular endothelial cells. J Biol Chem. 2001; 276: 44222-8. doi: 10.1074/jbc.M103942200.

29. Degenhardt F, Niklowitz P, Szymczak S, Jacobs G, Lieb W, Menke T, Laudes M, Esko T, Weidinger S, Franke A, Doring F, Onur S. Genome-wide association study of serum coenzyme Q10 levels identifies susceptibility loci linked to neuronal diseases. Hum Mol Genet. 2016; 25: 2881-91. doi: 10.1093/hmg/ddw134.

30. Nakamura K, Ohya W, Funakoshi H, Sakaguchi G, Kato A, Takeda M, Kudo T, Nakamura T. Possible role of scavenger receptor SRCL in the clearance of amyloid-beta in Alzheimer's disease. J Neurosci Res. 2006; 84: 874-90. doi: 10.1002/jnr.20992.

31. Panza F, Frisardi V, Capurso C, Imbimbo BP, Vendemiale G, Santamato A, D’Onofrio G, Seripa D, Sancarlo D, Pilotto A, Solfrizzi V. Metabolic syndrome and cognitive impairment: current epidemiology and possible underlying mechanisms. J Alzheimers Dis. 2010; 21: 691-724. doi: 
10.3233/JAD-2010-091669.

32. Lin E, Yang AC, Tsai SJ. Association between metabolic syndrome and cognitive function in old adults in a Taiwanese population. Taiwanese Journal of Psychiatry. in press.

33. Bai XH, Cho HR, Moodley S, Liu M. XB130-A Novel Adaptor Protein: Gene, Function, and Roles in Tumorigenesis. Scientifica (Cairo). 2014; 2014: 903014. doi: 10.1155/2014/903014.

34. Zhang R, Zhang J, Wu Q, Meng F, Liu C. XB130: A novel adaptor protein in cancer signal transduction. Biomed Rep. 2016; 4: 300-6. doi: 10.3892/br.2016.588.

35. Chen B, Liao M, Wei Q, Liu F, Zeng Q, Wang W, Liu J, Hou J, Yu X, Liu J. XB130 is overexpressed in prostate cancer and involved in cell growth and invasion. Oncotarget. 2016; 7: 59377-87. doi: 10.18632/oncotarget.11074.

36. Shi M, Zheng D, Sun L, Wang L, Lin L, Wu Y, Zhou M, Liao W, Liao Y, Zuo Q, Liao W. XB130 promotes proliferation and invasion of gastric cancer cells. J Transl Med. 2014; 12: 1. doi: 10.1186/1479-5876-12-1.

37. Brossard M, Fang S, Vaysse A, Wei Q, Chen WV, Mohamdi H, Maubec E, Lavielle N, Galan P, Lathrop M, Avril MF, Lee JE, Amos CI, et al. Integrated pathway and epistasis analysis reveals interactive effect of genetic variants at TERF1 and AFAP1L2 loci on melanoma risk. Int J Cancer. 2015; 137: 1901-9. doi: 10.1002/ijc.29570.

38. Insel KC, Merkle CJ, Hsiao CP, Vidrine AN, Montgomery DW. Biomarkers for cognitive aging part I: telomere length, blood pressure and cognition among individuals with hypertension. Biol Res Nurs. 2012; 14: 124-32. doi: 10.1177/1099800411406433.

39. Bhupatiraju C, Saini D, Patkar S, Deepak P, Das B, Padma T. Association of shorter telomere length with essential hypertension in Indian population. Am J Hum Biol. 2012; 24: 573-8. doi: 10.1002/ajhb.22264.

40. Allen BL, Taatjes DJ. The Mediator complex: a central integrator of transcription. Nat Rev Mol Cell Biol. 2015; 16: 155-66. doi: 10.1038/nrm3951.

41. Grueter CE. Mediator complex dependent regulation of cardiac development and disease. Genomics Proteomics Bioinformatics. 2013; 11: 151-7. doi: 10.1016/j. gpb.2013.05.002.

42. Schiano C, Casamassimi A, Vietri MT, Rienzo M, Napoli C. The roles of mediator complex in cardiovascular diseases. Biochim Biophys Acta. 2014; 1839: 444-51. doi: 10.1016/j.bbagrm.2014.04.012.

43. Krebs P, Fan W, Chen YH, Tobita K, Downes MR, Wood MR, Sun L, Li X, Xia Y, Ding N, Spaeth JM, Moresco EM, Boyer TG, et al. Lethal mitochondrial cardiomyopathy in a hypomorphic Med30 mouse mutant is ameliorated by ketogenic diet. Proc Natl Acad Sci U S A. 2011; 108: 19678-82. doi: 10.1073/pnas.1117835108.

44. Merkel M, Loeffler B, Kluger M, Fabig N, Geppert G, Pennacchio LA, Laatsch A, Heeren J. Apolipoprotein
AV accelerates plasma hydrolysis of triglyceride-rich lipoproteins by interaction with proteoglycan-bound lipoprotein lipase. J Biol Chem. 2005; 280: 21553-60. doi: 10.1074/jbc.M411412200.

45. Hsiao TJ, Hwang Y, Chang HM, Lin E. Association of the rs6235 variant in the proprotein convertase subtilisin/ kexin type 1 (PCSK1) gene with obesity and related traits in a Taiwanese population. Gene. 2014; 533: 32-7. doi: 10.1016/j.gene.2013.10.016.

46. Hsiao TJ, Lin E. A common rs7903146 variant of the transcription factor 7-like 2 gene is associated with type 2 diabetes mellitus and fasting glucose in a Taiwanese population. Diabetes Metab. 2017; 43: 83-5. doi: 10.1016/j. diabet.2016.05.003.

47. Lane HY, Tsai GE, Lin E. Assessing gene-gene interactions in pharmacogenomics. Mol Diagn Ther. 2012; 16: 15-27. doi: 10.2165/11597270-000000000-00000.

48. Hsiao TJ, Lin E. Evaluation of the glutamine 27 glutamic acid polymorphism in the adrenoceptor beta2 surface gene on obesity and metabolic phenotypes in Taiwan. J Investig Med. 2014; 62: 310-5. doi: 10.2310/ JIM.0000000000000030.

49. Lin E, Lane HY. Machine learning and systems genomics approaches for multi-omics data. Biomark Res. 2017; 5: 2. doi: 10.1186/s40364-017-0082-y.

50. Fan CT, Lin JC, Lee CH. Taiwan Biobank: a project aiming to aid Taiwan's transition into a biomedical island. Pharmacogenomics. 2008; 9: 235-46. doi: 10.2217/14622416.9.2.235.

51. Chen $\mathrm{CH}$, Yang JH, Chiang CWK, Hsiung CN, Wu PE, Chang LC, Chu HW, Chang J, Song IW, Yang SL, Chen YT, Liu FT, Shen CY. Population structure of Han Chinese in the modern Taiwanese population based on 10,000 participants in the Taiwan Biobank project. Hum Mol Genet. 2016; 25: 5321-31. doi: 10.1093/hmg/ddw346.

52. Lin E, Kuo PH, Liu YL, Yang AC, Kao CF, Tsai SJ. Effects of circadian clock genes and environmental factors on cognitive aging in old adults in a Taiwanese population. Oncotarget. 2017; 8: 24088-98. doi: 10.18632/ oncotarget.15493.

53. Lin E, Tsai SJ, Kuo PH, Liu YL, Yang AC, Kao CF. Association and interaction effects of Alzheimer's diseaseassociated genes and lifestyle on cognitive aging in older adults in a Taiwanese population. Oncotarget. 2017; 8: 24077-87. doi: 10.18632/oncotarget.15269.

54. Lin E, Tsai SJ, Kuo PH, Liu YL, Yang AC, Kao CF, Yang $\mathrm{CH}$. The rs1277306 Variant of the REST Gene Confers Susceptibility to Cognitive Aging in an Elderly Taiwanese Population. Dement Geriatr Cogn Disord. 2017; 43: 119-27. doi: 10.1159/000455833.

55. Lin E, Tsai SJ, Kuo PH, Liu YL, Yang AC, Kao CF, Yang $\mathrm{CH}$. The ADAMTS9 gene is associated with cognitive aging in the elderly in a Taiwanese population. PLoS One. 2017; 12: e0172440. doi: 10.1371/journal.pone.0172440. 
56. Liou YJ, Bai YM, Lin E, Chen JY, Chen TT, Hong CJ, Tsai SJ. Gene-gene interactions of the INSIG1 and INSIG2 in metabolic syndrome in schizophrenic patients treated with atypical antipsychotics. Pharmacogenomics J. 2012; 12: 5461. doi: $10.1038 /$ tpj.2010.74.

57. Hsiao TJ, Lin E. The ENPP1 K121Q polymorphism is associated with type 2 diabetes and related metabolic phenotypes in a Taiwanese population. Mol Cell Endocrinol. 2016; 433: 20-5. doi: 10.1016/j.mce.2016.05.020.

58. Hsiao TJ, Lin E. The Pro12Ala polymorphism in the peroxisome proliferator-activated receptor gamma (PPARG) gene in relation to obesity and metabolic phenotypes in a Taiwanese population. Endocrine. 2015; 48: 786-93. doi: 10.1007/s12020-014-0407-7.

59. Hsiao TJ, Hwang Y, Liu CH, Chang HM, Lin E. Association of the C825T polymorphism in the GNB3 gene with obesity and metabolic phenotypes in a Taiwanese population. Genes Nutr. 2013; 8: 137-44. doi: 10.1007/ s12263-012-0304-8.

60. Lou XY, Chen GB, Yan L, Ma JZ, Zhu J, Elston RC, Li MD. A generalized combinatorial approach for detecting gene-by-gene and gene-by-environment interactions with application to nicotine dependence. Am J Hum Genet. 2007; 80: 1125-37. doi: 10.1086/518312. 